Jurnal Ilmu Administrasi Publik 7 (2) (2019): 88-102

DOI: http://dx.doi.org/10.31289/publika.v7i2.2943

Jurnal Administrasi Publik

http://ojs.uma.ac.id/index.php/publikauma

\title{
Persepsi Publik Tentang Destinasi Pariwisata Danau Toba Sebagai Global Geopark Kaldera UNESCO
}

\author{
Taufik Wal Hidayat*, Irwan Nasution** \\ *Program Studi Ilmu Komunikasi, Universitas Medan Area, Medan, Indonesia \\ **Program Studi Administrasi Publik, Universitas Medan Area, Medan, Indonesia \\ Diterima Agustus 2019; Disetujui Oktober 2019; Dipublikasikan Desember 2019
}

\begin{abstract}
Abstrak
Persepsi publik yang dihasilkan tentang destinasi pariwisata Danau Toba sebagai global Geopark Kaldera UNESCO melalui website kompas.com di padukan dengan teori AIDDA (attention) perhatian khalayak informan/responden sebesar $65 \%$ tentang isu wacana Geopark Kaldera Toba memiliki hasil yang cenderung positif. Melalui teori AIDDA (interest) minat khalayak informan/responden sebesar $56 \%$ - 81,6\% menimbulkan ketertarikan terhadap isu wacana juga cenderung positif dan dengan teori AIDDA (desire) keinginan menimbulkan ketertarikan terhadap isu wacana destinasi pariwisata Danau Toba sebagai global Geopark Kaldera oleh UNESCO. Maka 71,6\% - 88,3\% khalayak infroman/responden tentu berkeinginan Danau Toba sebagai global Geopark Kaldera UNESCO memang cenderung positif. Hal lainnya yaitu (decision) keputusan dalam penyebaran isu wacana memiliki hasil yang cenderung positif serta (action) tindakan menghasilkan isu wacana destinasi pariwisata Danau Toba memiliki kecenderungan sebesar 88,3\%.
\end{abstract}

Kata kunci : Persepsi Publik, Danau Toba, Global Geopark Kaldera UNESCO, AIDDA

Public persepsion produced about Lake Toba tourism destinations as a global UNESCO Geopark Kaldera through the kompas.com website is combined with the AIDDA theory (attention) of the informant / respondent's attention of 65\% on the issue of the Toba Caldera Geopark discourse that has positive results. Through the theory of AIDDA (interest), the interest of the informant / respondent audience at 56\% 81.6\% raises interest in the issue of discourse also tends to be positive and with the AIDDA theory (desire) the desire raises interest in the issue of Lake Toba tourism destinations as UNESCO global Geopark Kaldera . So $71.6 \%$ - 88.3\% of the infroman / respondent audience certainly wants Lake Toba as a global UNESCO Geopark Caldera indeed tends to be positive. The other thing is the decision in the dissemination of the discourse issue has the results that tend to be positive and action producing the issue of the discourse of Lake Toba tourism destinations has a tendency of 88.3\%.

Keywords : Public Persepsion, Danau Toba, Global Geopark Kaldera UNESCO, AIDDA

How to Cite : Hidayat, W.T dan Nasution, I. (2019). Persepsi Publik Tentang Destinasi Pariwisata Danau Toba Sebagai Global Geopark Kaldera UNESCO 7 (2) : 88-102

\footnotetext{
*Corresponding author: P-ISSN-2549-9165

E-mail: taufikwalhidayat.staffuma.ac.id

e-ISSN -2580-2011
} 


\section{PENDAHULUAN}

Danau Toba adalah salah satu danau kaldera terbesar di dunia yang terletak di Provinsi Sumatera Utara, berjarak 176 km ke arah Barat Kota Medan. Danau Toba $\left(2,88^{\circ} \mathrm{N}-98,5^{\circ} 2 \mathrm{E}\right.$ dan $\left.2,35^{\circ} \mathrm{N}-99,1^{\circ} \mathrm{E}\right)$ adalah danau terluas di Indonesia (90 x 30 $\mathrm{km}^{2}$ ) dan juga merupakan sebuah kaldera volkano-tektonik (kawah gunung api raksasa) kuarter terbesar di dunia. Kaldera ini terbentuk oleh proses amblasan (collapse) pasca erupsi supervolcano gunung api Toba purba, kemudian terisi oleh air hujan.

Danau Toba mempunyai ukuran panjang $87 \mathrm{~km}$ berarah BaratlautTenggara dengan lebar $27 \mathrm{~km}$ dengan ketinggian 904 meter di atas permukaan laut (dpl) dan kedalaman danau yang terdalam 505 meter. Di tengah Danau Toba terdapat Pulau Samosir dengan ketinggian berkisar antara 900 hingga 1.600 meter dpl, yang terbentuk akibat pengangkatan dasar danau pasca erupsi kaldera yang terjadi pada 74.000 tahun yang lalu, sebagai akhir dari proses pencapaian kesetimbangan baru pascaerupsi kaldera supervolcano.

Kawasan dinding kaldera Toba memiliki morfologi perbukitan bergelombang sampai terjal dan lembah- lembah membentuk morfologi dataran dengan batas caldera rim watershed DTA (Daerah Tangkapan Air) Danau Toba dengan luas daerah tangkapan air (catchment area) $3.658 \mathrm{~km}^{2}$ dan luas permukaan danau $1.103 \mathrm{~km}^{2}$. Daerah tangkapan air ini berbentuk perbukitan ( $43 \%$ ), pegunungan (30\%) dengan puncak ketinggian 2.000 meter dpl (27\%) sebagai tempat masyarakat beraktifitas.

Sehubungan dengan keunikannya, Kaldera Toba diusulkan menjadi Geopark dengan nama Geopark Kaldera Toba (GKT). Untuk merealisasikan keinginan tersebut, dibentuk Tim Percepatan Pengajuan Geopark kaldera Toba menjadi anggota dalam Global Geopark Networking UNESCO, dengan menerbitkan Surat Keputusan Gubernur Sumatera Utara No. 188.44/404/KPTS/2013 pada tanggal 26 Juni 2013.

Keberadaan Danau Toba dengan keindahan alamnya menjadikan daerah di sekitarnya sebagai prioritas Objek dan Daya Tarik Wisata (ODTW) di Sumatera Utara. Saat ini kawasan Danau Toba ditetapkan sebagai Destinasi Pariwisata Nasional (DPN) dan Destinasi Pariwisata Unggul (DPU) di provinsi Sumatera Utara. Menyadari hal tersebut, pemerintah menetapkan Kawasan Danau Toba (KDT) 
sebagai Kawasan Strategis Nasional (KSN) bidang pariwisata yang selanjutnya disebut sebagai Kawasan Strategis Pariwisata Nasional.

Semenjak dicetuskannya Danau Toba sebagai global Geopark kaldera UNESCO, maka ruang lingkup kawasan kaldera Toba yang menjadi daerah tangkapan air (DTA) mampu menunjang sebagai destinasi pariwisata Geopark kaldera Toba yang terbagi menjadi 7 kawasana Kabupaten meliputi Kab. Dairi, Kab. Humbang Hasundutan, Kab. Toba Samosir, Kab. Karo, Kab. Tapanuli Utara, Kab. Simalungun, dan Kab. Samosir. (sumber:http://ppsu.co.id)

Adapun 16 situs geologi (geosite) yang ada di kawasan Geopark kaldera Toba yakni Sipiso-piso Tongging, Silahi Sabungan, Haranggaol, Huta Ginjang, Pusuk Buhit, Sibaganding, Taman Eden Tobasa, Balige Liang Sipege Meat, blok uluan air terjun Situmurun, Muara Sibandang, Sipinsur, Bakara Tipang, Tele Panguruan, Huta Tinggi Danau Sisihoni, Simanindo Batu Hoda, Ambarita Tuktuk dan Tomok. (sumber:http://ppsu.co.id)

Berdasarkan pedoman GGN UNESCO, tujuan Geopark adalah menggali, mengembangkan, menghargai, dan mengambil manfaat dari hubungan erat antara warisan geologi dan segi lainnya dari warisan alam, berupa budaya, dan nilai - nilai di area tersebut. Untuk mencapai tujuan tersebut, sebuah Geopark harus memiliki batas-batas yang ditetapkan dengan jelas dan memiliki kawasan yang cukup luas untuk pembangunan ekonomi lokal. Sehingga, di dalam Geopark harus berlangsung sedikitnya tiga kegiatan penting, yaitu: konservasi, pendidikan, dan geowisata.

Menurut Data BPS Sumatera Utara menyebutkan, kunjungan Wisatawan mancanegara ke Geopark kaldera Toba sepanjang tahun 2017 mengalami peningkatan yang signifikan, yakni 12,02 persen dibandingkan periode sama 2016 menjadi 261.736 orang. Dimana wisatawan Malaysia pada tahun 2017 mencapai 123.551 orang atau naik 6,98 persen dari 2016. Sementara Singapura sebanyak 17.005, RRT 8.005 dan Australia 4.972 kunjungan. (sumber: http://sumut.bps.go.id)

Menurut Albig dalam (Juanda ,2004) persepsi publik adalah pendapat suatu pernyataan mengenai masalah yang kontroversial, persepsi publik mempunyai 2 unsur yaitu pernyataan dan masalah kontroversial. 
Menurut (Juanda , 2004) ada 4 hal yang menyebabkan timbulnya suatu persepsi publik, yaitu:

1. Adanya suatu masalah atau situasi yang bersifat kontroversional.

2. Adanya publik yang secara spontan terpikat kepada suatu masalah, melibatkan diri ke dalam masalah tersebut dan berusaha untuk memberikan pendapatnya.

3. Adanya kesempatan untuk bertukar pikiran atau berdebat mengenai masalah yang kontroversial oleh suatu publik.

4. Adanya interaksi dari individuindividu dalam publik yang menghasilkan suatu pendapat yang bersifat kolektif untuk diekspresikan. Perkataan kolektif dalam hubungan ini diartikan sebagai suatu pendapat yang dapat diterima oleh individu-individu dalam publik yang bersangkutan dan yang tidak ada pertentangan lagi dari pihak yang lain.

Dalam hal ini, Presiden Joko Widodo pada tanggal 1 Juni 2016 telah menandatangani Peraturan Presiden Nomor 49 Tahun 2016 tentang Badan Otorita Pengelola Kawasan Pariwisata Danau Toba. Dalam Perpres ini disebutkan, untuk melaksanakan pengembangan Kawasan Pariwisata Danau Toba dengan membentuk Badan Otoritas Pengelola Kawasan Pariwisata Danau Toba yang berada di bawah dan bertanggung jawab kepada Presiden.

Saat ini Kawasan Danau Toba telah ditetapkan sebagai Kawasan Strategis Nasional (KSN) berdasarkan PP Nomor 26 Tahun 2008. Selain itu Danau Toba juga ditetapkan sebagai Destinasi Pariwisata Nasional (DPN) dan Kawasan Strategis Pariwisata Nasional (KSPN) sesuai dengan PP Nomor 50 Tahun 2011 tentang Rencana Induk Pengembangan Kepariwisataan Nasional yang menjadikan Danau Toba sebagai salah satu dari sepuluh prioritas pengembangan kepariwisataan nasional.

\section{METODE PENELITIAN}

Metodologi penelitian yang digunakan adalah matode penelitian penelitian deskriptif kuantitatif. Metode deskriptif dapat diartikan sebagai prosedur pemecahan masalah yang diselidiki dengan menggambarkan atau melukiskan keadaan subjek/objek penelitian, baik itu seseorang, lembaga, masyarakat dan yang lainnya pada saat sekarang, berdasarkan fakta-fakta yang 
tampak atau sebagaimana adanya" (Nawawi, 2001).

Adapun jenis penelitian yang digunakan dalam penelitian ini adalah penelitian kuantitatif dengan pendekatan deksriptif, menurut (Sugiyono, 2013) metode penelitian kuantitatif dapat diartikan sebagai metode penelitian yang berlandaskan pada filsafat positivisme, digunakan untuk meneliti pada populasi atau sampel tertentu, teknik pengambilan sampel secara random, pengumpulan data menggunakan instrument penelitian, analisis data bersifat kuantitatif/statistik dengan tujuan untuk menguji hipotesis yang telah di tetapkan.

Populasi dalam suatu penelitian merupakan kumpulan individu atau obyek yang merupakan sifat-sifat umum. (Arikunto, 2010) menjelaskan bahwa "populasi adalah keseluruhan subjek penelitian." Populasi dalam penelitian ini adalah Mahasiswa FISIP USU berjumlah 600 orang.

Dalam penelitian ini teknik pengambilan sampel yang digunakan adalah random sampling. Maka sampling ini setiap unsur dari keseluruhan populasi memmpunyai kesempatan yang sama untuk dipilih, dimana setiap sampel memiliki interprestasi berupa pengalaman, mengetahui dan mengunjungi destinasi pariwisata Geopark Kaldera Danau Toba. Peneliti mengambil sampel sebanyak 60 orang atau 10\% 15\% dari jumlah populasi 600 .

Teknik pengumpulan data adalah langkah yang paling strategis dalam penelitian, karena tujuan utama dari penelitian adalah mendapatkan data. Untuk itu teknik pengumpulan data yang akan dilakukan dalam penelitian ini adalah menggunakan angket. Angket yang digunakan dalam penelitian ini adalah angket semi terbuka. Angket bersifat semi terbuka yaitu jawaban sudah disediakan

Adapun analisis yang digunakan dalam penelitian ini bersifat deskriptif dengan menggunakan tabel distribusi frekuensi tunggal (Sugiyono, 2016).

\section{HASIL DAN PEMBAHASAN}

Penelitian ini dilakukan dengan cara membagikan angket dimana di dalamnya terdapat 20 pertanyaan yang berhubungan dengan kerangka pemikiran kepada Mahasiswa maka peneliti memperoleh hasil penelitian yang kemudian di jelaskan dalam bentuk tabel sebagai berikut. 
Tabel 1. Memuat Informasi Isu Geopark Kaldera Toba

\begin{tabular}{|l|l|c|c|}
\hline No & Jawaban & Frekuensi & $\begin{array}{l}\text { Persentase } \\
(\%)\end{array}$ \\
\hline 1 & Mengetahui & 9 & 15 \\
\hline 2 & $\begin{array}{l}\text { Kurang } \\
\text { mengetahui }\end{array}$ & 24 & 40 \\
\hline 3 & $\begin{array}{l}\text { Tidak } \\
\text { mengetahui }\end{array}$ & 27 & 45 \\
\hline & Jumlah & 60 & 100 \\
\hline
\end{tabular}

Sumber: data primer

Berdasarkan tabel 1 diatas maka dapat diperoleh data yang menunjukkan bahwa 9 (15\%) responden mengetahui tentang wacana Geopark Kaldera Toba, sedangkan 24 (40\%) responden kurang mengetahui berita informasi tentang isu wacana Geopark Kaldera Toba pada situs dan 27 (45\%) responden tidak mengetahui berita informasi tentang isu wacana Geopark Kaldera Toba. Hal ini menunjukkan bahwa responden tidak mengetahui tentang informasi isu wacana Geopark Kaldera Toba.

Tabel 2. Informasi Isu Danau Toba Menjadi Geopark Kaldera

\begin{tabular}{|l|l|c|c|}
\hline No & Jawaban & Frekuensi & $\begin{array}{c}\text { Persentase } \\
(\%)\end{array}$ \\
\hline 1 & Tertarik & 39 & 65 \\
\hline 2 & $\begin{array}{l}\text { Kurang } \\
\text { tertarik }\end{array}$ & 17 & 28,3 \\
\hline 3 & $\begin{array}{l}\text { Tidak } \\
\text { tertarik }\end{array}$ & 4 & 6,6 \\
\hline & Jumlah & 60 & 100 \\
\hline
\end{tabular}

Sumber : data primer
Berdasarkan tabel 2 diatas maka dapat diperoleh data yang menunjukkan bahwa 39 (65\%) responden tertarik untuk mencari tahu informasi isu wacana kawasan Danau Toba menjadi Geopark Kaldera oleh UNESCO, sedangkan 17 $(28,3)$ kurang tertarik mencari tahu informasi isu wacana kawasan Danau Toba menjadi Geopark Kaldera oleh UNESCO dan hanya $4(6,6 \%)$ responden tidak tertarik mencari informasi isu wacana kawasan Danau Toba menjadi Geopark Kaldera oleh UNESCO.

Hal ini menunjukkan bahwa mayoritas responden ingin mencari tahu informasi isu wacana kawasan Danau Toba menjadi Geopark Kaldera oleh UNESCO.

Tabel 3. Pembangunan Infrastruktur

Wisata Toba Dimuat Kompas.Com

\begin{tabular}{|l|c|c|c|}
\hline No & Jawaban & Frekuensi & $\begin{array}{c}\text { Persentase } \\
(\%)\end{array}$ \\
\hline 1 & Setuju & 20 & 33,3 \\
\hline 2 & $\begin{array}{c}\text { Kurang } \\
\text { setuju }\end{array}$ & 26 & 43,3 \\
\hline 3 & $\begin{array}{c}\text { Tidak } \\
\text { setuju }\end{array}$ & 14 & 23,3 \\
\hline & Jumlah & 60 & 100 \\
\hline
\end{tabular}

Sumber: data primer

Berdasarkan tabel 3 di atas maka diperoleh data yang menunjukkan bahwa $20 \quad(33,3 \%) \quad$ responden setuju pembangunan infrastruktur dengan biaya 
3,3 Milyar untuk menunjang wisata Geopark Kaldera Toba, sedangkan 26 $(43,3 \%)$ responden kurang setuju dalam hal pembangunan infrastruktur yang menghabiskan biaya 3,3 Milyar untuk menunjang wisata Geopark Kaldera Toba dan hanya $14(23,3 \%)$ responden yang sama sekali tidak setuju dengan pembangunan infrastruktur yang menghabiskan biaya 3,3 Milyar untuk menunjang wisata Geopark Kaldera Toba. Hal ini menunjukkan mayoritas responden kurang setuju pembangunan infrastruktur dengan biaya 3,3 Milyar hanya untuk menunjang wisata Geopark Kaldera Toba.

Tabel 4. Pemerintah Pusat Menjadikan Pariwisata Nasional

\begin{tabular}{|c|c|c|c|}
\hline No & Jawaban & Frekuensi & $\begin{array}{c}\text { Persentase } \\
(\%)\end{array}$ \\
\hline 1 & $\begin{array}{c}\text { Sangat } \\
\text { setuju }\end{array}$ & 33 & 55 \\
\hline 2 & Setuju & 26 & 43,3 \\
\hline 3 & $\begin{array}{c}\text { Tidak } \\
\text { setuju }\end{array}$ & 1 & 1,6 \\
\hline & Jumlah & 60 & 100 \\
\hline
\end{tabular}

Sumber: data primer

Berdasarkan tabel 6 di atas maka dapat diperoleh data yang menunjukkan bahwa 33 (55\%) responden sangat setuju Pemerintah Pusat menjadikan isu kawasan Geopark Kaldera Toba sebagai destinasi pariwisata nasional dan kawasan strategis pariwisata nasional yang dimuat di kompas.com, sedangkan 26 (43,3\%) responden setuju Pemerintah Pusat menjadikan isu kawasan Geopark Kaldera Toba sebagai destinasi pariwisata nasional dan kawasan strategis pariwisata nasional yang dimuat di kompas.com dan hanya $1(1,6 \%)$ responden tidak setuju Pemerintah Pusat Pemerintah Pusat menjadikan isu kawasan Geopark Kaldera Toba sebagai destinasi pariwisata nasional dan kawasan strategis pariwisata nasional. Hal ini menunjukkan bahwa mayoritas responden sangat setuju atau mendukung penuh Pemerintah Pusat menjadikan isu kawasan Geopark Kaldera Toba sebagai destinasi pariwisata nasional dan kawasan strategis pariwisata nasional.

Tabel 5. Pemerintah Daerah menjadikan Danau Toba sebagai ikon

\begin{tabular}{|l|c|c|c|}
\hline No & Jawaban & Frekuensi & $\begin{array}{c}\text { Persentase } \\
(\%)\end{array}$ \\
\hline 1 & $\begin{array}{c}\text { Sangat } \\
\text { setuju }\end{array}$ & 35 & 58,3 \\
\hline 2 & Setuju & 23 & 38,3 \\
\hline 3 & $\begin{array}{c}\text { Tidak } \\
\text { setuju }\end{array}$ & 2 & 3,3 \\
\hline & Jumlah & 60 & 100 \\
\hline
\end{tabular}

Sumber: data primer

Berdasarkan tabel 7 di atas maka dapat diperoleh data yang menunjukkan bahwa $35(58,3 \%)$ responden sangat 
setuju Pemerintah Provinsi Sumatera Utara akan menjadikan isu Geopark Kaldera Toba sebagai ikon pariwisata untuk meningkatkan kunjungan wisatawan, sedangkan 23 (38,3\%) setuju Pemerintah Provinsi Sumatera Utara akan menjadikan isu Geopark Kaldera Toba sebagai ikon pariwisata untuk meningkatkan kunjungan wisatawan dan hanya $2(3,3 \%)$ responden tidak setuju Pemerintah Provinsi Sumatera Utara akan menjadikan isu Geopark Kaldera Toba sebagai ikon pariwisata untuk meningkatkan kunjungan wisatawan. Ini menunjukkan bahwa mayoritas responden sangat setuju atau mendukung penuh Pemerintah Provinsi Sumatera Utara akan menjadikan isu Geopark Kaldera Toba sebagai ikon pariwisata untuk meningkatkan kunjungan wisatawan.

Tabel 6. Kerusakan hutan di Danau Toba mengancam Geopark Toba

\begin{tabular}{|c|c|c|c|}
\hline No & Jawaban & frekuensi & $\begin{array}{c}\text { Persentase } \\
(\%)\end{array}$ \\
\hline 1 & Setuju & 50 & 83,3 \\
\hline 2 & $\begin{array}{c}\text { Kurang } \\
\text { setuju }\end{array}$ & 10 & 16,6 \\
\hline 3 & $\begin{array}{c}\text { Tidak } \\
\text { setuju }\end{array}$ & - & - \\
\hline & Jumlah & 60 & 100 \\
\hline
\end{tabular}

Sumber: data primer
Berdasarkan tabel 6 di atas maka dapat diperoleh data yang menunjukkan bahwa $50(83,3 \%)$ responden setuju bila kerusakan hutan di wilayah tangkapan air Danau Toba mengancam kelestarian Geopark Kaldera Toba, sedangkan 10 $(16,6 \%)$ responden kurang setuju kerusakan hutan di wilayah tangkapan air Danau Toba mengancam kelestarian Geopark Kaldera Toba. Hal ini menunjukkan mayoritas responden setuju bila kerusakan hutan di wilayah tangkapan air Danau Toba mengancam kelestarian Geopark Kaldera Toba.

Tabel 7. Keppres Tentang Pembentukan Badan Pengelolaan

\begin{tabular}{|l|l|c|c|}
\hline No & Jawaban & Frekuensi & $\begin{array}{c}\text { Persentase } \\
(\%)\end{array}$ \\
\hline 1 & Setuju & 54 & 90 \\
\hline 2 & $\begin{array}{l}\text { Kurang } \\
\text { setuju }\end{array}$ & 5 & 8,3 \\
\hline 3 & $\begin{array}{l}\text { Tidak } \\
\text { setuju }\end{array}$ & 1 & 1,6 \\
\hline & Jumlah & 60 & 100 \\
\hline
\end{tabular}

Sumber: data primer

Berdasarkan tabel 7 di atas maka dapat diperoleh data yang menunjukkan bahwa 54 (90\%) responden setuju keputusan presiden tentang pembentukan badan pengelolaan Geopark Kaldera Toba untuk memaksimalkan kebijakan dan strategi pemerintah dalam pembangunan pariwisata di Sumut, sedangkan $5(8,3 \%)$ 
responden tidak setuju keputusan presiden tentang pembentukan badan pengelolaan Geopark Kaldera Toba untuk memaksimalkan kebijakan dan strategi pemerintah dalam pembangunan pariwisata di Sumut dan hanya $1(1,6 \%)$ responden tidak setuju dengan keputusan presiden tentang pembentukan badan pengelolaan Geopark Kaldera Toba untuk memaksimalkan kebijakan dan strategi pemerintah dalam pembangunan pariwisata di Sumut. Maka hal ini menunjukkan mayoritas responden setuju dengan keputusan presiden tentang pembentukan badan pengelolaan Geopark Kaldera Toba untuk memaksimalkan kebijakan dan strategi pemerintah dalam pembangunan pariwisata di Sumut

Tabel 8. Pemerintah Pusat akan membangun infrastruktur

\begin{tabular}{|c|l|c|c|}
\hline No & Jawaban & Frekuensi & $\begin{array}{c}\text { Persentase } \\
(\%)\end{array}$ \\
\hline 1 & Setuju & 26 & 43,3 \\
\hline 2 & $\begin{array}{l}\text { Kurang } \\
\text { setuju }\end{array}$ & 30 & 50 \\
\hline 3 & $\begin{array}{l}\text { Tidak } \\
\text { setuju }\end{array}$ & 4 & 6,6 \\
\hline & Jumlah & 60 & 100 \\
\hline
\end{tabular}

Sumber: data primer

Berdasarkan tabel 8 di atas maka dapat diperoleh data yang menunjukkan bahwa $26(43,3 \%)$ responden setuju pemerintah pusat akan membuat infrastruktur jalan lingkar Danau Toba menghabiskan biaya 20 Milyar hingga 97 Milyar demi meningkatkan wisatawan ke destinasi wisata prioritas Geopark Kaldera Toba, sedangkan 30 (50\%) responden kurang setuju pemerintah pusat akan membuat infrastruktur jalan lingkar Danau Toba menghabiskan biaya 20 Milyar hingga 97 Milyar demi meningkatkan wisatawan ke destinasi wisata prioritas Geopark Kaldera Toba yang dimuat pada kompas.com dan hanya $4 \quad(6,6 \%)$ responden tidak setuju pemerintah pusat akan membuat infrastruktur jalan lingkar Danau Toba menghabiskan biaya 20 Milyar hingga 97 Milyar demi meningkatkan wisatawan ke destinasi wisata prioritas Geopark Kaldera Toba. Hal ini menunjukkan bahwa mayoritas responden tidak setuju pemerintah pusat akan membuat infrastruktur jalan lingkar Danau Toba menghabiskan biaya 20 Milyar hingga 97 Milyar demi meningkatkan wisatawan ke destinasi wisata prioritas Geopark Kaldera Toba. 
Tabel 9. Bila Danau Toba menjadi Geopark

\begin{tabular}{|l|l|c|c|}
\hline No & Jawaban & Frekuensi & $\begin{array}{c}\text { Persentase } \\
(\%)\end{array}$ \\
\hline 1 & Tentu & 53 & 88,3 \\
\hline 2 & $\begin{array}{l}\text { Belum } \\
\text { tentu }\end{array}$ & 7 & 11,6 \\
\hline 3 & Tidak & - & - \\
\hline & Jumlah & 60 & 100 \\
\hline
\end{tabular}

Sumber: data primer

Berdasarkan tabel 9 di atas maka dapat diperoleh data yang menunjukkan bahwa 53 (88,3\%) responden tentu ingin berkunjung atau menjadi destinasi wisata mereka bila Danau Toba dicetuskan sebagai Geopark (taman bumi/situs warisan dunia) oleh UNESCO, sedangkan 7 $(11,6 \%)$ responden belum tentu ingin berkunjung atau menjadi destinasi wisata mereka. Hal ini menunjukkan bahwa mayoritas responden tentu ingin berkunjung atau menjadi destinasi wisata mereka bila Danau Toba dicetuskan sebagai Geopark (taman bumi/situs warisan dunia) oleh UNESCO.

Tabel 10. Apa Anda mengetahui Geopark

Kaldera Toba

\begin{tabular}{|l|l|c|c|}
\hline No & Jawaban & Frekuensi & $\begin{array}{l}\text { Persentase } \\
(\%)\end{array}$ \\
\hline 1 & Mengetahui & 14 & 23,3 \\
\hline 2 & $\begin{array}{l}\text { Kurang } \\
\text { mengetahui }\end{array}$ & 39 & 65 \\
\hline 3 & $\begin{array}{l}\text { Tidak } \\
\text { mengetahui }\end{array}$ & 7 & 11,6 \\
\hline & Jumlah & 60 & 100 \\
\hline
\end{tabular}

Sumber: data primer
Berdasarkan tabel 10 di atas maka dapat diperoleh data yang menunjukkan bahwa 14 (23,3\%) responden mengetahui apa itu Geopark Kaldera Toba, sedangkan 39 (65\%) responden tidak mengetahui apa itu Geopark Kaldera Toba dan hanya 7 $(11,6 \%)$ responden tidak mengetahui sama sekali apa itu Geopark Kaldera Toba. Hal ini menunjukkan bahwa mayoritas responden kurang mengetahui apa itu Geopark Kaldera Toba.

Tabel 11. Setujukah Anda Danau Toba menjadi Geopark oleh UNESCO

\begin{tabular}{|l|l|c|c|}
\hline No & Jawaban & Frekuensi & $\begin{array}{c}\text { Persentase } \\
(\%)\end{array}$ \\
\hline 1 & $\begin{array}{l}\text { Sangat } \\
\text { setuju }\end{array}$ & 43 & 71,6 \\
\hline 2 & Setuju & 16 & 26,6 \\
\hline 3 & $\begin{array}{l}\text { Kurang } \\
\text { setuju }\end{array}$ & 1 & 1,7 \\
\hline & Jumlah & 60 & 100 \\
\hline
\end{tabular}

Sumber: data primer

Berdasarkan tabel 13 di atas maka dapat diperoleh data yang menunjukkan bahwa $43(71,6 \%)$ responden sangat setuju bila Danau Toba menjadi Geopark (taman bumi) oleh UNESCO, sedangkan 16 (26,6\%) responden setuju bila Danau Toba menjadi Geopark (taman bumi) oleh UNESCO dan hanya $1(1,7 \%)$ responden kurang setuju bila Danau Toba menjadi Geopark (taman bumi) oleh UNESCO. Maka hal ini menunjukkan bahwa 
mayoritas responden sangat setuju dan mendukung penuh bila Danau Toba menjadi Geopark (taman bumi) oleh UNESCO.

Tabel 12. Menurut Anda wisata budaya di Danau Toba menarik

\begin{tabular}{|l|l|c|c|}
\hline No & Jawaban & Frekuensi & $\begin{array}{c}\text { Persentase } \\
(\%)\end{array}$ \\
\hline 1 & Menarik & 49 & 81,6 \\
\hline 2 & $\begin{array}{l}\text { Kurang } \\
\text { menarik }\end{array}$ & 10 & 16,6 \\
\hline 3 & $\begin{array}{l}\text { Tidak } \\
\text { menarik }\end{array}$ & 1 & 1,7 \\
\hline & Jumlah & 60 & 100 \\
\hline
\end{tabular}

Sumber: data primer

Berdasarkan tabel 12 di atas maka dapat diperoleh data yang menunjukkan bahwa $49(81,6 \%)$ responden mengatakan wisata budaya Danau Toba menarik, sedangkan $10 \quad(16,6 \%)$ responden mengatakan wisata budaya Danau Toba kurang menarik dan hanya 1 (1,7\%) mengatakan wisata budaya Danau Toba tidak menarik. Hal ini menunjukkan bahwa mayoritas responden mengatakan wisata budaya di Danau Toba menarik.

Tabel 13. Konsep Geopark Kaldera Toba

\begin{tabular}{|l|l|c|c|}
\hline No & Jawaban & Frekuensi & $\begin{array}{l}\text { Persentase } \\
(\%)\end{array}$ \\
\hline 1 & Setuju & 55 & 91,6 \\
\hline 2 & $\begin{array}{l}\text { Kurang } \\
\text { setuju }\end{array}$ & 5 & 8,3 \\
\hline 3 & $\begin{array}{l}\text { Tidak } \\
\text { setuju }\end{array}$ & - & - \\
\hline & Jumlah & 60 & 100 \\
\hline
\end{tabular}

Sumber: data primer
Berdasarkan tabel 13 diatas maka dapat diperoleh data yang menunjukkan bahwa $55(91,6 \%)$ responden setuju Konsep Geopark Kaldera Toba memadukan keragaman geologi, keragaman hayati (biodiversity) dan budaya (culture diversity) yang di manfaatkan untuk pembangunan dan kesejahteraan masyarakat, sedangkan 5 $(8,3 \%)$ responden kurang setuju Konsep Geopark Kaldera Toba memadukan keragaman geologi, keragaman hayati (biodiversity) dan budaya (culture diversity) yang di manfaatkan untuk pembangunan dan kesejahteraan masyarakat. Artinya bahwa mayoritas responden setuju Konsep Geopark Kaldera Toba memadukan keragaman geologi, keragaman hayati (biodiversity) dan budaya (culture diversity) yang di manfaatkan untuk pembangunan dan kesejahteraan masyarakat.

Tabel 14. Pemerintah Pusat dan Daerah memaksimalkan sosialisasi

\begin{tabular}{|l|l|l|l|}
\hline No & Jawaban & Frekuensi & $\begin{array}{l}\text { Persentase } \\
(\%)\end{array}$ \\
\hline 1 & Setuju & 29 & 48,3 \\
\hline 2 & $\begin{array}{l}\text { Kurang } \\
\text { setuju }\end{array}$ & 22 & 36,6 \\
\hline 3 & $\begin{array}{l}\text { Tidak } \\
\text { setuju }\end{array}$ & 9 & 15 \\
\hline & Jumlah & 60 & 100 \\
\hline
\end{tabular}

Sumber: data primer 
Berdasarkan tabel 14 diatas maka dapat diperoleh data yang menunjukkan bahwa $29(48,3 \%)$ responden setuju Pemerintah Pusat dan Pemerintah Daerah Provinsi Sumatera Utara telah memaksimalkan sosialisasi isu Geopark Kaldera Toba sebagai situs warisan dunia atau taman bumi oleh UNESCO, sedangkan $22(36,6 \%)$ responden kurang setuju Pemerintah Pusat dan Pemerintah Daerah Provinsi Sumatera Utara telah memaksimalkan sosialisasi isu Geopark Kaldera Toba sebagai situs warisan dunia atau taman bumi oleh UNESCO dan hanya $9(15 \%)$ responden tidak setuju Pemerintah Pusat dan Pemerintah Daerah Provinsi Sumatera Utara telah memaksimalkan sosialisasi isu Geopark Kaldera Toba sebagai situs warisan dunia atau taman bumi oleh UNESCO. Maka hal ini menunjukkan bahwa mayoritas responden setuju Pemerintah Pusat dan Pemerintah Daerah Provinsi Sumatera Utara telah memaksimalkan sosialisasi isu Geopark Kaldera Toba sebagai situs warisan dunia atau taman bumi oleh UNESCO.

Persepsi adalah pernyataan tentang sikap mengenai suatu masalah tertentu yang bersifat kontroversial yang timbul sebagai pembicaraan tentang masalah kontroversi yang menimbulkan pendapat yang berbeda-beda, dan ciri dari persepsi publik adanya isu yang dapat didefinisikan sebagai situasi yang kontemporer yang mungkin tidak terdapat kesepakatan dan isu mengandung konflik kontemporer yang sebagaimana peneliti jabarkan kedalam angket dimana terdapat isu-isu persepsi publik tentang destinasi pariwisata Danau Toba sebagai Geopark Kaldera UNESCO melalui new media website kompas.com.

Dalam penelitian ini dapat digambarkan bahwa informasi isu persepsi publik tentang destinasi pariwisata Danau Toba sebagai global Geopark Kaldera UNESCO melalui new media website kompas.com diharapkan memunculkan perhatian, minat, hasrat, keputusan, dan tindakan atas isu wacana destinasi pariwisata Danau Toba sebagai global Geopark Kaldera UNESCO.

\section{Perhatian (attention)}

Perhatian khalayak dalam hal ini adalah persepsi Mahasiswa isu wacana Geopark Kaldera Toba memiliki 65\% mayoritas persepsi yang dihasilkan menarik perhatian khalayak (persepsi) Mahasiswa/Mahasiswi Departemen Ilmu Komunikasi USU untuk memberikan perhatian atau mencari tahu isu wacana 
kawasan Danau Toba menjadi Geopark Kaldera Toba oleh UNESCO tentang berita informasinya.

Sedangkan dalam perhatian khalayak (persepsi) informasi tentang isu Geopark Kaldera Toba oleh UNESCO menghasilkan 45\% kurang mengetahui tentang isu wacana Geopark Kaldera Toba namun dengan adanya angket menggugah perhatian para informan/responden untuk memberikan perhatian kepada isu tersebut, hingga menimbulkan atensi atau menarik perhatian khalayak informan/responden terhadap isu wacana destinasi pariwisata Danau Toba sebagai global Geopark Kaldera sehingga dapat menimbulkan daya tarik bagi khalayak informan/responden mengenai informasi isu wacana destinasi pariwisata Danau Toba.

\section{Minat (interest)}

Dengan adanya perhatian khalayak informan/responden maka diharapkan perhatian tersebut akan menimbulkan minat atau ketertarikan terhadap isu wacana destinasi pariwisata Danau Toba sebagai Geopark Kaldera. Kategori wisata di Danau Toba yaitu wisata alam, wisata rohani, wisata konvensi (buatan), wisata budaya dan wisata agrowisata yang mempunyai daya tarik 56\% hingga 81,6\% khalayak informan/responden sehingga memunculkan minat atau ketertarikan terhadap wisata di Danau Toba.

\section{Keinginan (desire)}

Keinginan untuk merasakan, menikmati, memakai dan menyaksikan langsung harus dapat dibangkitkan yaitu dengan menimbulkan ketertarikan terhadap isu wacana destinasi pariwisata Danau Toba sebagai global Geopark Kaldera oleh UNESCO. Peneliti memberikan pertanyaan berupa bila Danau Toba dicetuskan sebagai Geopark Kaldera Toba membuat berkeinginan mengunjungi dan menjadi tujuan destinasi pariwisata mereka, maka 71,6\% hingga 88,3\% infroman/responden tentu berkeinginan Danau Toba menjadi global Geopark Kaldera (taman bumi) oleh UNESCO serta menjadikan tujuan kebutuhan wisata khalayak informan/responden.

\section{Keputusan (decision)}

Pada tahap ini ketertarikan berhasil diciptakan menjadi sebuah kebutuhan. Khalayak informan/responden harus diyakinkan agar dapat membuat keputusan untuk dapat langsung menikmati dan mengunjungi destinasi wisata Danau Toba dengan kategori daya tarik wisata alam, 
daya tarik wisata budaya, daya tarik wisata konvensi (buatan), daya tarik wisata rohani, dan daya tarik agrowisata. Namun, dalam penyebaran isu wacana destinasi pariwisata Danau Toba sebagai Geopark Kaldera UNESCO dalam penyebaran angket maka khalayak informan/responden memberikan keputusan kurang setuju dalam hal demi meningkatkan wisatawan ke destinasi wisata prioritas Geopark Kaldera Toba maka pemerintah pusat akan membuat infrastruktur jalan lingkar Danau Toba menghabiskan biaya 20 Milyar hingga 97 Milyar. maka khalayak/responden memberikan keputusan mayoritas yaitu sebesar $50 \%$.

\section{Tindakan (action)}

Tahapan ini merupakan tahapan akhir yang akan dilakukan oleh khalayak informan/responden setelah tahap perhatian, minat, keinginan, dan keputusan yaitu dengan 88,3\% khalayak mengunjungi wisata Danau Toba untuk melihat, menikmati dan menyaksikan langsung destinasi tersebut.

\section{KESIMPULAN}

Berdasarkan hasil penelitian dapat ditarik beberapa kesimpulan sebagai berikut:
1. Persepsi publik yang dihasilkan tentang destinasi pariwisata Danau Toba sebagai global Geopark Kaldera UNESCO melalui website kompas.com di padukan dengan teori AIDDA (attention) perhatian khalayak informan/responden sebesar $65 \%$ tentang isu wacana Geopark Kaldera Toba cenderung positif.

2. Persepsi publik yang dihasilkan tentang destinasi pariwisata Danau Toba sebagai global Geopark Kaldera UNESCO melalui website kompas.com melalui teori AIDDA (interest) minat khalayak informan/responden sebesar 56\% - 81,6\% menimbulkan minat atau ketertarikan terhadap isu wacana destinasi pariwisata Danau Toba sebagai Geopark Kaldera UNESCO cenderung positif.

3. Persepsi publik yang dihasilkan tentang destinasi pariwisata Danau Toba sebagai global Geopark Kaldera UNESCO melalui website kompas.com dengan teori AIDDA (desire) keinginan menimbulkan ketertarikan terhadap isu wacana destinasi pariwisata Danau Toba sebagai global Geopark Kaldera oleh UNESCO. maka 71,6\% - 88,3\% khalayak infroman/responden tentu berkeinginan Danau Toba sebagai 
global Geopark Kaldera UNESCO cenderung positif.

4. Persepsi publik yang dihasilkan tentang destinasi pariwisata Danau Toba sebagai global Geopark Kaldera UNESCO melalui website kompas.com dengan teori AIDDA (decision) keputusan dalam penyebaran isu wacana destinasi pariwisata Danau Toba sebagai Geopark Kaldera UNESCO maka cenderung positif.

5. Persepsi publik yang dihasilkan tentang destinasi pariwisata Danau Toba sebagai global Geopark Kaldera UNESCO melalui website kompas.com melalui teori AIDDA (action) tindakan menghasilkan isu wacana destinasi pariwisata Danau Toba sebesar 88,3\% khalayak informan/responden segera melakukan tindakan mengunjungi Danau Toba sebagai destinasi pariwisata mereka maka cenderung positif.

\section{DAFTAR PUSTAKA}

Arikunto, Suharsimi., dkk. 2008. Penelitian Tindakan Kelas. Jakarta: Bumi Aksara..

Arikunto. 2010. Prosedur Penelitian: Suatu Pendekatan Praktek. Jakarta: Rineka Cipta.

Bungin, Burhan. 2015. Komunikasi Pariwisata (Tourism Cummnucation) Pemasaran
Dinas Pariwisata, Seni dan Budaya Kabupaten Samosir.2012. Buku Informasi Objek Wisata Samosir.

Effendy, Onong Uchjana. 2000. Ilmu, Teori dan Filsafat Komunikasi. Bandung : PT. Citra Aditya Bakti.

Hasan, M. Iqbal. 2002. Pokok-pokok Materi Metodologi Penelitian dan Aplikasinya. Bogor: Ghalia Indonesia.

Helena, O dan Novi, E. 2017. Persepsi Publik. Jakarta: PT. Indeks.

Juanda, Khalid. 2004. Persepsi Publik dan Komunikasi Sosial. Bandung: Citra Adtya Bakti.

Kasali, Rhenald. 1994. Manajemen Publicrelations: Konsep dan Aplikasinya Di Indonesia. Jakarta: Pustaka Utama Grafiti.

Moleong, Lexy. 2004. Metode Penelitian Kualitatif. Jakarta: Raja Grafindo Persada.

Sastropoetro, Santoso. 1990. Komunikasi Sosial. Bandung: Remaja Rosdakarya.

Sugiyono, 2015. Metode Penelitian Pendidikan (Pendekatan Kuantitatif, Kualitatif dan R\&D). Bandung: CV. Alfabeta. 